\title{
TRANSITION PROCESSES IN LITHUANIA AND OTHER EAST - AND CENTRAL EUROPEAN COUNTRIES: DEVELOPMENT OF UNIVERSITY AND PROFESSIONAL STUDIES SYSTEM
}

\author{
Borisas Melnikas \\ Department of International Economy and Management Vilnius Gediminas Technical University, \\ Sauletekio al.11,LT-10223 Vilnius, Lithuania.E-mail:melnikas@vv.vtu.lt
}

Received 10 January 2004; accepted 29 April 2004

\begin{abstract}
The present state of university and professional education in Lithuania and major problems of its development are outlined. The possibilities of upgrading university and professional studies are evaluated, taking into account the processes associated with the integration of Lithuania into the European Union. In addition, the prospects of education development are analyzed in the context of transitions characteristic of the states of Central and Eastern Europe.
\end{abstract}

Key words: transition processes, university and professional studies.

\section{Introduction}

Problem formulation. At present, complex transition processes take place in Lithuania as well as in other countries of Central and Eastern Europe. They embrace nearly all spheres of life as well as having the impact on social development of the country. [1-7].

An essential feature of the present stage of transition is the intense preparation for the integration into the European Union. This implies that the problems and prospects of transitions should be evaluated from the perspective of integration into $\mathrm{EU}[2,4,5]$.

In the process of integration of Lithuania into $\mathrm{EU}$, the priority should be given to the investigation of human resources and their potential, quality and adaptation in the European Union. The solution of the problem of human resources development is, in turn, closely connected with the upgrading of university and professional studies and the integration of this system into an integral educational system of the EU countries. This means that at the preparation stage for integrating into EU an urgent problem arises associated with the development of university and professional studies in Lithuania in compliance with the standards accepted in the EU countries as well as the adaptation of studies to the requirements determined by:

- the formation of common labour market in EU,

- fast advance of technology, intense internationalization of economy,

- the formation of information society,

- new forms of competition,

- new prospects for developing international cooperation in the area of university and professional studies.

Goals and objectives of the present research. A major goal of the research is to outline the potentialities of upgrading university and professional studies in Lithuania and integrating them into the educational system of EU countries.

Major problems to be solved in achieving the stated goal are as follows:

- to determine the aims and priorities in developing university and professional studies in Lithuania, 
- to outline major features of the development of the countries of Central and Eastern Europe in the transition period, taking into account the great influence of transition on the development of university and professional studies,

- to state the priorities in the process of university and professional studies integration into the integral education system of EU countries.

The results obtained. Major results of the research are as follows:

- most relevant problems and the structure of the priorities in university and professional studies in Lithuania are outlined,

- major features of transitions, taking place in the countries of Central and Eastern Europe, are determined and their impact on the development of studies evaluated,

- the system of the priorities in university and professional studies in Lithuania in the integration into the unified EU educational system is established.

Let us consider the above issues in more detail.

\section{University and professional studies in Lithuania, major problems of their development and the priorities of upgrading}

The possibilities of modernization of university and professional studies are a very important factor of political, social, economic and technological development, especially in the Eastern and Central Europe [3, 4, 8-11].

At present, the system of higher education in Lithuania is characterized by great diversity, depending on the following factors:

- the existence of various types of institutions providing higher education are found, i.e. wide scope universities, specialized universities (technological, law, agricultural, pedagogical, medicine, etc.) and academies with the rights of universities, as well as colleges (non - university higher schools),

- the university studies may involve 3 stages (Bachelor's, Master's and Doctor's degrees), as well as university professional studies (i.e. engineering and others) ; in addition, a number of colleges provide non - university professional education,

- both state and private educational institutions provide their services in the educational system of the country.
Professional education is also provided by high, professional schools, various study centers, courses, etc.

The state of higher education may be assessed, taking into account its positive and negative characteristics.

Positive factors are as follows :

- higher education in Lithuania has traditionally been of high quality : during the last 30 years the system of higher education in Lithuania has been and still is one of the best in the countries of Central and Eastern Europe, being distinguished by high level of studies and training of specialists. This tradition has great impact on current development of education [12].

- great emphasis is placed on thorough theoretical background, providing the graduates with universal knowledge helping them to adapt to constantly changing requirements,

- the potential of system of higher education in Lithuania allows it to provide the studies in practically all specialities needed by the country, with the priority given to most urgently needed and popular specialities,

- professors and other academic staff are induced to carry out the research work, with the emphasis placed on their participation in international projects and publishing of papers,

- the international links with foreign higher schools are extended, the priority given to the EU universities: more and more students from Lithuania have practical work or study for 1 or 2 semesters in Western countries, acquiring adequate knowledge and experience.

The negative factors are as follows :

- the system of higher education in Lithuania is not completely prepared to train great numbers of specialists for developing and application of high - level technologies. The students usually are given only a general outline of higher - level technologies in their area of study, not allowing them to create and use these advanced methods,

- programs of studies in higher institutions do not address the actual needs of the labour market. The graduates are often obliged to retrain, being unable to find a job according to the speciality obtained (therefore, it may be stated that the structure of the academic programs and specializations in the system of education is not adequate to economical structure and employment potentialities),

- the students do not acquire sufficient practical knowledge and skills. This may be accounted for various reasons, such as the lack of practical 
training during the studies, insufficient involvement of students into the research work, the lack of practical experience of some teachers, poorly equipped laboratories, etc.,

- a number of higher institutions lack the academic spirit. Most of higher institutions in Lithuania, like those in other countries of Central and Eastern Europe, borrowed many symbols and attributes of Western universities, failing to maintain the psychological climate and traditions characteristic of them.

The major problems presently facing university and professional education may be described as follows :

- despite the traditional high level, the quality of studies is no longer meeting the requirements, one of the most important problems associated with inability to create in Lithuania $a$ system of criteria adequately assessing the quality of studies, as well as the efficiency of the research carried out by the academic staff in satisfying the actual needs of the state and society (the current system of evaluating the quality of studies and efficiency of research is based on minor factors, giving the priority to quantitative parameters, ignoring quality - based criteria, involving the assessment of the contents of studies, level of actual knowledge, competence and professionalism of the lectures). The lack of the adequate system of criteria prevents the solution of studies upgrading problems, associated with

- the lack of close relationship between the priorities of studies and current and future trends of market development,

- studies do not adequately address the development and application of high - level technologies, students are not sufficiently involved into research work, their creative potential not being used and developed in full,

- higher schools are not sufficiently specialized. As a result, human resources and intellectual potential are not properly concentrated, specialists are "scattered", thus making the level of education lower than it could be if the experienced highly qualified specialists were concentrated in a particular area of studies, research or practical work,

- state financing of studies does not meet the actual needs of the country and the society. Despite declaring fair and noble principles pursuing the state policy towards financing the higher education, the real financial support is aimed to satisfy the demands of a particular academic elite (recently, some competing groups have been struggling to realize state financing schemes corresponding to their interests, which are often dramatically different from the interests of the society),

- the relations among the academic staff often lack tolerance, friendliness and culture: all forms of selfishness may be observed, preventing from efficient development of the whole system of studies,

- the scope of cooperation between the universities and other higher schools of Lithuania and Western countries is not sufficient: under the conditions of Lithuania's integration into the European Union, the cooperation should be more intense, involving much wider areas and forms of contacts. These problems are of paramount importance, therefore, they should be given the priority in development of studies.

The above problems should be considered in the general context of transition and integration into the European Union [4, 13] .

\section{Transitions as a general context of developing the university and professional studies in Lithuania}

The development and upgrading of university and professional studies in Lithuania may be approached from two various perspectives :

- on the one hand, the upgrading of studies and the development of higher education is an important part of general system of transitions,

- on the other hand, the upgrading of studies and the development of higher education is a_necessary condition of intensifying and promoting further development of transition processes [5, 6].

In both approaches the priority is given to the problems of transitions: major features of political, social and economic development of Eastern and Central European countries in recent $10-15$ years have been transitions representing complex dramatical changes in all spheres of life. $[1,5-8,14,15]$. Taking into account that transitions indicate a major trend of political, social and economic development of these countries, the states of Eastern and Central Europe are referred to as transition countries.

Political, economic and social development in the transition countries is characterized by some features common to all of these countries as well as by specific features characteristic only of some transition states. [4]. The ability to determine both general and specific features of transformations allows us to define the situation in a particular country, the priorities of its development as well as identifying and solving most urgent problems. 
In determining general features representing major trends of political, social and economic development in a transition period, the following most important issues should be emphasized:

1. Constant orientation toward the new quality life, implying that in the period of transition the efforts are made to realize the norms, standards, ideals, and stereotypes of new quality life. The changes associated with the quality of life take place in the period of transition, which are aimed at changing life for the better. Thus, a new society based on such values as democracy, humanism and openness as well as declaring the priority of human rights, freedom and well - being has been formed in the states of Eastern and Central Europe in the time of transition.

2. A complex character of transitions, meaning that major changes are complex, embracing major areas of political, social and economic life as well as the development of modern technologies, environment protection, laws and other areas of social importance. A complex character of transitions may be considered one of the major features characteristic of the development of Eastern and Central European countries. In recent $10-15$ years the qualitative changes have taken place in the political, social and economic structures of the society, while a new scale of values, life styles and priorities has been introduced and a new social order combining the elements of Western democracy and some Eastern Europe's traditions has been established.

3. Moreover, the complexity of transitions in these countries manifests itself in versatile effects on various sides of life, which may be controversially assessed, because the results of the changes are not definitely outlined. The uneven character of transitions, implying that social changes often take place as a leap forward from one quality to another, These leaps are also characterized by profound and sudden changes. It is important to note that in the period of transition the society may experience shocks, when the traditional values and priorities are suddenly rejected, being replaced with some new values, of which the people have only superficial knowledge not being ready to adopt them. In the transition period, the formation of some political, social, economic, cultural and ideological vacuum is usually observed in the countries of Eastern and Central Europe due to a sudden character of changes often accompanied by instability.

4. Simultaneous and controversial character of transitions, meaning that different transitions may and do take place simultaneously, being, however, conflicting and imbalanced. As a result, the situation arises when one kind of transition is contrary to the others, which in turn may cause problems and even stresses in the society. The experience of the states of Eastern and Central Europe provides a lot of examples of controversial transitions, when, say, social and economic changes contradict the political transitions, while the changes taking place in some countries of Eastern and Central Europe do not conform with the transitions occurring in other states or regions of the same territory. Such negative phenomena, hampering the advance of the above states, call for the idea of harmonizing the transitions of controversial character, implying balancing of different changes.

5. The innovative character of transitions, meaning that any transition accumulates some novelty. In the transition period, the innovative potential is intensely developed by providing the conditions for innovative activities. The novel character of transitions may be expressed in two ways : first, the conditions are created for adapting well known models and solutions to some situation in a new way. In this case, they are considered to be innovative. Second, completely new, previously unknown models and solutions are made. In this case, these newly created patterns, having no analogues, are considered to be the innovations. The development of two types of novelties in the transition period emphasizes the importance of innovative activities for the countries of Eastern and Central Europe.

6. A positive character of transitions, implying that transitions yield positive results in most cases. In spite of the fact, that both positive and negative results are actually obtained in the conditions of transition, the predominance of positive results is a particular feature of transitions.

7. The idealistic and disappointing character of transitions, meaning that this period is characterized by the recurrence of "searching for the ideals - disappointment" cycles. The above cyclicity shows that at the beginning of transition the solution of urgent problems is usually associated with the achievement of certain ideals, while later the period of disappointment both in the very ideals and in the transition itself and its outcome, follows. For example, in the transition period in the countries of Eastern and Central Europe it was much expected from democratization and free market development. However, later the community was much disappointed with the results 
obtained. At the same time, the cycles of "idealization - disappointment" demonstrate the maturing of the society in the course of transition as well as its adaptability to actual environment.

8. Openness in the period of transitions, meaning that the tradition of openness, publicity and "transparency" becomes established, making it possible to develop democracy and free market economy. However, it is evident that the patterns of "the open society" being formed in the countries of Eastern and Central Europe do not completely conform with the long - standing traditions of openness existing in Western countries, especially in Europe. Nevertheless, the developing tendency of openness in the states of Eastern and Central Europe is generally considered as one of the major development trends in the transition period.

9. Harmonization of objective and subjective elements, implying that the character and orientation of transitions largely depend on a number of objective factors characterizing the objectively existing background of political, social and economic transformations as well as on subjective elements, reflecting personal interests, influence and lobbyist activities of various subjects (i.e. individuals, groups of people of various levels, clans, etc.). The above objective and subjective elements are characterized by certain degree of coordination and harmonization, therefore the harmony of these two factors should be considered as naturally determined phenomenon of the development of Eastern and Central European countries in the transition period. It should be noted that subjective factors play particularly important role : the interests of individual persons, groups of people of various levels, clans, etc. have a considerable effect on the political, social and economic development of these countries.

10.Integrity and comparable character of transitions on a world scale, meaning that local transitions are integrated into the higher - level transition systems. This indicates that the above transitions are of an international character, promoting the process of globalization as well as internationalization of political, social and economic development and demonstrating that they are comparable and can be coordinated at an international level. It may be stated that the transitions taking place in the countries of Eastern and Central Europe are of paramount importance for their integration into the global and international political, social, economic, cultural and infor- mation structures, as well as being a factor contributing to the convergence of the mentality and lifestyles of the inhabitants of various countries.

11. The resonance factor, conditioning that transitions of various origin and nature could coincide in time. Therefore, the community has to endure a heavy burden of a number of transitions taking place simultaneously. The phenomenon of resonance indicates itself as the timing of political, social and economic changes causing a heavy burden on the community, which in turn may threaten its safety and stability.

The above - listed appropriate phenomena show general trends of transitions, which are universal and similar in all the states of Eastern and Central Europe. Along with these major trends some specific features may be observed in political, social and economic development of particular countries or groups of countries. The above trends are particularly characteristic of transitions taking place in the Baltic countries, including Lithuania. the Baltic region is specific in many ways, therefore the transitions taking place in it may be considered a specific case of conformity to natural laws $[4,7,12,14,15]$.

The following features of transitions may be specially mentioned as mostly characteristic of the Baltic states, including Lithuania:

1. Higher resonance of transitions, implying that in the Baltic states some additional transitions associated with regaining independence and forming new modern states as well as the priority of integration into the Western system took place alongside the political, social and economic transitions characteristic of other countries of Eastern and Central Europe. This means that the transition resonance in the Baltic states was caused not only by the democratization of market relations common to Eastern and Central European countries, but also by the transitions associated with very rapid development of new national states and their integration into the Western system. Thus, transitions in the Baltic states were more diverse and extensive than those taking place in other countries of Eastern and Central Europe. Therefore, it may be stated that the higher transition resonance is a major characteristic feature of the Baltic region.

2. The conflicting character of national priorities and regional integration and internationalization trends, indicating that two opposite as well as mutually complementary tendencies are developed in the Baltic states. On the one hand, national businesses are seeking autonomy, even closeness and self-isolation, 
trying to get established on the national market by the exclusive right. On the other hand, the tendency of integration of the whole Baltic region and the cooperation of three Baltic states in political, social and economic areas is constantly growing. Though three Baltic states often compete with each other, more and more possibilities are revealed to pursue the unified policy of cultural, economic and information development.

Needless to say, that some more specific features of transitions taking place in the Baltic states may be identified. Undoubtedly, they may refer to one of these countries, for example, Lithuania. The transitions taking place only in one of the states may be referred to as individual features characterizing the development of a particular state.

Thus, the analysis of individual features of transitions taking place in Lithuania enables us to determine the effect of various geographical characteristics (e.g. configuration of neighboring countries, exceptional geographic position of Kaliningrad region and the like) on their development. Some other individual and specific factors also influence the transition processes in Lithuania. Among them are cultural and historical features (e.g. the influence of the catholic ethics, the development of Lithuanian state and the formation of Lithuanian nation, urbanization, the location of agricultural zones, etc.).

The specific features of transitions taking place in Lithuania complete a general system of naturally determined trends of development in the periods of transformations. The proper understanding of these phenomena helps to improve the political, cultural, social and economic life.

Further investigation and evaluation of naturally determined transitions and their major features would allow the states of Eastern and Central Europe to pursue more efficient policy of improving the conditions of development as well as promoting the integration of these countries into international political, social and economic structures.

All these factors play an important part in university and professional studies.

\section{The priorities of integrating university and professional studies in Lithuania into the integral education system of the European Union}

In the conditions of increasing integration of Lithuania and other countries of Central and Eastern Europe into EU and other Western institutions, the integration of their systems of university and professional studies into the integral education system of EU countries has to be efficiently developed. This implies that the priorities of integration of studies should be stated. In this process the functions of university and professional studies in Lithuania in the integral education system of EU countries should be determined. The above functions may include :

- purposeful complex training of specialists and research development aimed at extending economic, technological and informational activity of EU, including both Central and Eastern Europe and Russia, and other regions of the former USSR,

- organization of specialized studies aimed to train and adapt specialists for extending EU to the East, as well as for work in Lithuania and other countries of Central and Eastern Europe to promote their integration into EU economic, technological and information areas,

- training of specialists and performing research in Lithuania and other countries in special areas, in which high quality potential for science and education development and Lithuanian leadership may be created. The determination of the function of university and professional studies in Lithuania allows us to outline the priorities of the education system integration into the EU system. They may be as follows:

1. Specialization of university and professional studies in Lithuania along the following lines:

- training of specialists in EU countries for the activities in Eastern regions;

- training of specialists in EU countries for specific activities associated with creation and application of particular high - level technologies as well as with manufacture of particular products in specific areas, where Lithuania may become one of the leaders,

- training of specialists to meet the needs of Lithuanian social and economic development.

2. Organizing research in the areas of training specialists;

3. Intense internationalization and europeanization of education in Lithuania, including:

- extensive introduction of joint programs of studies prepared by Lithuania and its foreign partners, with the possibility for students provided to continue their studies in other (primarily, Western Europe) countries after taking some courses in Lithuania (with general type qualification certificates granted to the graduates),

- establishment of foreign universities and their 
branches, departments and chairs in Lithuania, thus making available for Lithuanians and citizens from other countries to get the education provided by foreign universities in this country,

- the introduction of open university and distant training on a large scale.

4. The integration of studies with large projects of economic, technological and social development and upgrading: this priority implies that the system of studies both in Lithuania and other countries should address general problems of the European Union and their solution.

The realization of the above priority issues may create the basis for comprehensive modernization of university and professional studies in Lithuania in compliance with the standards of the integral EU education system.

\section{Conclusions and recommendations}

In solving the problems, relevant for university and professional studies in Lithuania, a special emphasis should be placed on the following issues:

- the need for the upgrading of studies should be recognized, discussed and satisfied in the context of Lithuania's integration into EU and the development and upgrading the European Union in view of globalization processes, information society formation and the occurrence of new forms of competition and modern technologies; this approach may be effective in making the studies in Lithuania an open, dynamic and adaptable system,

- the updating of studies should address positive transitions in society,

- the studies should be organized in Lithuania in such a way that would promote the formation of the society with high standard of life, giving the priority to intellectual labour, high - level technologies and manufacture of quality goods,

- the system of studies should be integrated into the international, primarily EU, system of education. In upgrading the system of education in Lithuania, the research and design work should be developed along the following lines :

- major functions of higher education in Lithuania in developing human resources, as well as promoting the extension and modernization of EU, should be identified,

- long - term strategy of rational specialization of higher and other schools in Lithuania and increasing their potential should be developed,
- the possibilities of promoting the involvement of the universities of the EU countries and other states in the academic life of Lithuania should be investigated,

- open and distant education should be extended, with the respective research and projects undertaken.

Further investigation of the development of university and professional studies in Lithuania may be an efficient tool of promoting the transition processes and integration of Lithuania into the European Union.

\section{References}

1. The Globalization of World Politics: An Introduction to International Relations / Ed. J. Baylis, S. Smith. Oxford: Oxford University Press, 1997. 526 p.

2. Lane J.E., Ersson S.O. European Politics: An Introduction. London: Sage Publications, 1996. 238 p.

3. Means G., Schneider D. Meta Capitalism. The e. Business Revoliution and the Design of 21 st Century Companies and Markets. Chichester: John Wiley and Sons, 2000. 208 p.

4. Melnikas B. Tranformacijos. Vilnius: Vaga, 2002. 750 p.

5. Politische und oekonomische Transformation in Osteuropa / Hrsg. G. Brunner. Baden: Nomos, 2000. 252 S.

6. Pollert A. Transformation at Work: In the New Market Economies of Central Eastern Europe. London: Sage Publications, 1999. 272p.

7. The Technology of Transition. Ed. D. A. Dyker. Budapest, Central European University Press, 1997. 292 p.

8. Harris P., Wring D. Political Marketing. Oxford: Butterworth and Heinemann, 2000. 256 p.

9. Judson A.S. Making Strategy Hopen: Transforming Plans info Reality. Oxford: Blackwell Publishers, 1996. $250 \mathrm{p}$.

10. Lamentowicz W. Šių laikų valstybè. Vilnius: Alma Littera, 1998. $120 \mathrm{p}$.

11. Rosenzweig P. Accelerating International Growth. Chichester: John Wiley and Sons, 2001. 275 p.

12. Melnikas B., Melnikas L. Aktuelle politische und wirtschaftliche Situation in Litauen. Koeln, Bundesinstitut fuer ostwissenschaftliche und internationale Studien, Sondernveroffentlichung, 1995. $50 \mathrm{~S}$.

13. Swanson J. L., Fonad N. A. Career Theory and Practice. London: Sage Publications, 1999. 264 p.

14. Melnikas B. Menedžmentas ir transformacijos Rytų Europos šalyse. Vilnius: Lietuvos karo akademija, 1995. $157 \mathrm{p}$.

15. Melnikas B. Probleme der Integration der baltischen Laender in westliche Strukturen. Koeln, Bundesinstitut fuer ostwissenschaftliche und internationale Studien, N 40, 1999. 40S. 